University of Nebraska - Lincoln

DigitalCommons@University of Nebraska - Lincoln

\title{
Mixed-Grass Prairie Canopy Structure and Spectral Reflectance Vary with Topographic Position
}

\author{
Rebecca L. Phillips \\ USDA-ARS, rebecca.phillips@ars.usda.gov \\ Moffatt K. Ngugi \\ USDA-ARS \\ John Hendrickson \\ USDA-ARS, john.hendrickson@ars.usda.gov \\ Aaron Smith \\ Ducks Unlimited \\ Mark West \\ USDA-ARS
}

Follow this and additional works at: https://digitalcommons.unl.edu/usdaarsfacpub

Phillips, Rebecca L.; Ngugi, Moffatt K.; Hendrickson, John; Smith, Aaron; and West, Mark, "Mixed-Grass Prairie Canopy Structure and Spectral Reflectance Vary with Topographic Position" (2012). Publications from USDA-ARS / UNL Faculty. 1276.

https://digitalcommons.unl.edu/usdaarsfacpub/1276

This Article is brought to you for free and open access by the U.S. Department of Agriculture: Agricultural Research Service, Lincoln, Nebraska at DigitalCommons@University of Nebraska - Lincoln. It has been accepted for inclusion in Publications from USDA-ARS / UNL Faculty by an authorized administrator of DigitalCommons@University of Nebraska - Lincoln. 


\title{
Mixed-Grass Prairie Canopy Structure and Spectral Reflectance Vary with Topographic Position
}

\author{
Rebecca L. Phillips • Moffatt K. Ngugi • \\ John Hendrickson • Aaron Smith • Mark West
}

This article is a U.S. government work, and is not subject to copyright in the United States.

Received: 12 March 2011 / Accepted: 31 July 2012/Published online: 9 September 2012

(C) Springer Science+Business Media, LLC (outside the USA) 2012

\begin{abstract}
Managers of the nearly 0.5 million ha of public lands in North and South Dakota, USA rely heavily on manual measurements of canopy height in autumn to ensure conservation of grassland structure for wildlife and forage for livestock. However, more comprehensive assessment of vegetation structure could be achieved for mixed-grass prairie by integrating field survey, topographic position (summit, mid and toeslope) and spectral reflectance data. Thus, we examined the variation of mixed-grass prairie structural attributes (canopy leaf area, standing crop mass, canopy height, nitrogen, and water content) and spectral vegetation indices (VIs) with variation in topographic position at the Grand River National Grassland (GRNG), South Dakota. We conducted the study on a 36,000-ha herbaceous area within the GRNG, where randomly selected plots $\left(1 \mathrm{~km}^{2}\right.$ in size) were geolocated and included summit, mid and toeslope positions. We tested for effects of topographic position on measured vegetation attributes and VIs calculated from Landsat TM and Advanced Spaceborne Thermal Emission and Reflection Radiometer (ASTER) data collected in July 2010. Leaf area, standing crop mass, canopy height, nitrogen, and water content were lower at summits than at toeslopes. The
\end{abstract}

R. L. Phillips $(\bowtie) \cdot$ M. K. Ngugi · J. Hendrickson

United States Department of Agriculture (USDA),

Agricultural Research Service (ARS), 1701 10th Avenue nw,

Mandan, ND 58554, USA

e-mail: rebecca.phillips@ars.usda.gov

\section{A. Smith}

Ducks Unlimited, 2525 River Road, Bismarck, ND 58503, USA

M. West

United States Department of Agriculture (USDA),

Agricultural Research Service (ARS), 2150 Centre Avenue,

Fort Collins, CO 80526, USA simple ratio of Landsat Band 7/Band 1 (SR71) was the VI most highly correlated with canopy standing crop and height at plot and landscape scales. Results suggest field and remote sensing-based grassland assessment techniques could more comprehensively target low structure areas at minimal expense by layering modeled imagery over a landscape stratified into topographic position groups.

Keywords Landsat - ASTER - Remote sensing · Biomass · VOR · Canopy height

\section{Introduction}

The US Forest Service (USFS) grassland management plan requires public lands within the Dakota Prairie Grasslands (DPG) provide forage for domestic livestock as well as wildlife habitat. Maintenance of grassland canopy structure is important for nesting and predation cover for many avian species (Larivière 2003). Grassland assessments often rely on visual obstruction reading (VOR) data collected at random points after livestock removal in autumn (Svingen 2009). Collecting VOR data require that large field crews work at remote locations, where $<1 \%$ of the total land area is physically surveyed (Sjursen 2009; Uresk and Juntti 2008). Synoptic data available from satellite-borne sensors could facilitate comprehensive assessment of current grassland condition using parameters known to vary with structure, such as standing crop biomass or leaf area (Chen 1996; Washington-Allen and others 2006). As managers are faced with additional demands and shrinking resources, new approaches for grassland assessment are needed to inform adaptive management strategies. Elevation data coupled with data derived from satellite-borne sensors and field surveys might be used to develop creative applications 
that complement existing efforts with economical grassland assessment tools.

The Robel pole is commonly used to measure VOR as an indicator of canopy height (Robel and others 1970). One reason for the wide acceptance of this particular method as an indicator of structure is the strong correlation between height and standing crop biomass, which was reported for grasslands in Texas (Vermiere and others 2002), Wyoming (Uresk and Juntti 2008), South Dakota (Uresk and Benson 2007) Oklahoma (Vermiere and Gillen 2001) and Kansas (Robel and others 1970). These correlations indicate the Robel pole measurement integrates both stand height and density, thereby providing a proxy for vegetation structure. Other variables indicative of grassland canopy structure are less-easily measured, such as percentage of bare ground cover, percentage of mid-grass versus short-grass cover, leaf area, photosynthetically-active vegetation (PV) mass, non-photosynthetically active vegetation (NPV) mass, canopy water content, litter depth, and phenology (Fisher and Davis 2010). Structure at a broader scale may also be important for defining landscape descriptors, such as patch size, habitat patch length and Shannon's diversity index (Luoto and others 2004).

Remote-sensing systems generally acquire data suitable for the evaluation of a grassland's horizontal dimension (e.g. standing crop mass, nitrogen content), given their established sensitivity to variations in pigment (Moran and others 1997; Hunt and others 2003; Beeri and others 2007). Several spectral indices available from Landsat TM and Advanced Spaceborne Thermal Emission and Reflection Radiometer (ASTER) are known to co-vary with grassland properties during the growing season (Moran and others 1997; Hunt and others 2003), particularly the chlorophyllbased indices such as the normalized difference vegetation index (NDVI) and the enhanced vegetation index (EVI). These indices rely on the spectral reflectance contrast between red and near-infrared (NIR) bands. NDVI and EVI are sensitive to leaf chlorophyll content, which tends to increase with standing crop, particularly where leaf area index values are $<2.5$ (Roberts and others 1998). Other indices, such as those that use the mid-infrared (Mid-IR) range of data, are more sensitive to leaf water content of vegetation (Hardinsky and others 1983; Hunt and Rock 1989). Spectra in the blue region (Landsat 5 Band 1; $0.45-0.52 \mu \mathrm{m})$ are sensitive to atmospheric scattering, which minimize atmospheric interference in other wavebands (Ceccato and others 2002; Moran and others 1997). Canopies with low water contents would be more reflective in the Mid-IR than canopies with higher water contents (Ceccato and others 2002). A simple ratio using blue band data in the denominator and Mid-IR in the numerator, such as Landsat TM Band 7/Band 1 (SR71), will increase with reflectance in the Mid-IR and when scatter in the blue band decreases. Simple ratios between two bands minimize shadow effects (Lawrence and Ripple 1998) and may be more strongly correlated with grassland height than normalized vegetation indices (Hall and others 2010).

Grassland topographic position often affects vegetation composition (Milchunas and others 1989; Knapp and others 1993) and reflectance (Moran and others 1997), so topographic and reflectance data could be combined to assist with landscape-scale vegetation assessments. Freely available DEM data from the US Geological Survey (Gesch and others 2002) represent underlying surface topography, and these data assist with identifying those more static landscape features associated with geomorphology. Widely available, passive sensor data from satellite-borne platforms such as Landsat TM and MODIS depict seasonal changes in vegetation reflectance, such as productivity and greenness. Current data available from imagery are important for grasslands because structural attributes, such as height and standing crop, vary substantively during the growing season in response to weather and land use (Roberts and others 1998). The application of these low-cost indicators of productivity, however, is largely driven by scale (Beeri and others 2005). For example, daily indicators of productivity (such as NDVI) collected from the MODIS sensor do not provide the level of spatial resolution needed to assess vegetation changes within a square kilometer. Here, we test a data application within the constraints of scale and cost using remote-sensing based data (Landsat TM and ASTER), DEM and field data.

Our objective was to develop a low-cost method for threshold-based assessment of grassland vegetation canopies for a 36,000 ha landscape. We aimed to model DEM, satellite-based spectra and field-based canopy structure data to determine how canopy structure and spectra vary with topographic position (summit, midslope and toeslope). Data collections during peak growing season were needed because these broadband spectral indices indicate productivity when plants are green. The first step in this process was to determine if mixed-grass prairie summits found at the GRNG were lower in structure than at other topographic positions, as reported for shortgrass (Milchunas and others 1989; Singh and others 1998) and tallgrass prairie (Knapp and others 1993). We hypothesized these mixed-grass prairie structural characteristics, including leaf area, standing crop mass, canopy height, canopy nitrogen (N) mass, and canopy water content would be lower at summits than at toeslopes. In accordance with changes in canopy cover characteristics from summits to toeslopes, we hypothesized summit NDVI values would be lower and SR71 values would be higher at summits than at toeslopes. We used the pre-established Robel pole management minimum value of $9 \mathrm{~cm}$ to guide selection of a spectral index value indicative of this height threshold. If summit 
vegetation were below the canopy height threshold even at peak standing-crop, this would indicate a need to stratify the landscape by topographic position prior to landscape assessment.

\section{Methods}

Landscape Description, Classification, and Stratification

The GRNG is located in northwestern South Dakota, USA $\left(45.7^{\circ} \mathrm{N}, 102.5^{\circ} \mathrm{W}\right.$; Fig. 1$)$ within the Northern Great Plains ecoregion (Omernik 1987). About $75 \%$ of the annual precipitation $(350 \mathrm{~mm})$ occurs during the growing season (April-September). Average monthly temperature is highest in July $\left(21^{\circ} \mathrm{C}\right)$ and lowest in January $\left(-9^{\circ} \mathrm{C}\right)$. Topography ranges from open plains to rolling grassland prairie, with elevations from 670 to $880 \mathrm{~m}$. Soils are predominantly well-drained, moderately deep, moderately permeable, fine-loamy, mixed, superactive, frigid Typic Argiustolls (NRCS 2011). The GRNG is a mixed-grass prairie ecosystem characterized by blue grama [Bouteloua gracilis (H. B. K.) Lag. Ex Griffiths] and western wheatgrass [Pascopyron smithii (Rybd) Lőve]. Many of the GRNG lowlands were farmed in the early twentieth century and are now stands of crested wheatgrass [Agropyron cristatum (L.) Gaertn.]. The GRNG is seasonally grazed by
Fig. 1 Location of the 36,000 ha landscape-of-interest at the Grand River National Grassland (GRNG) near Lemmon, SD. The four colors indicate different historical reflectance index (HRI) groups, which was based on an unsupervised classification of a 10-year MODIS EVI data set. Locations of the field plots are outlined in bold

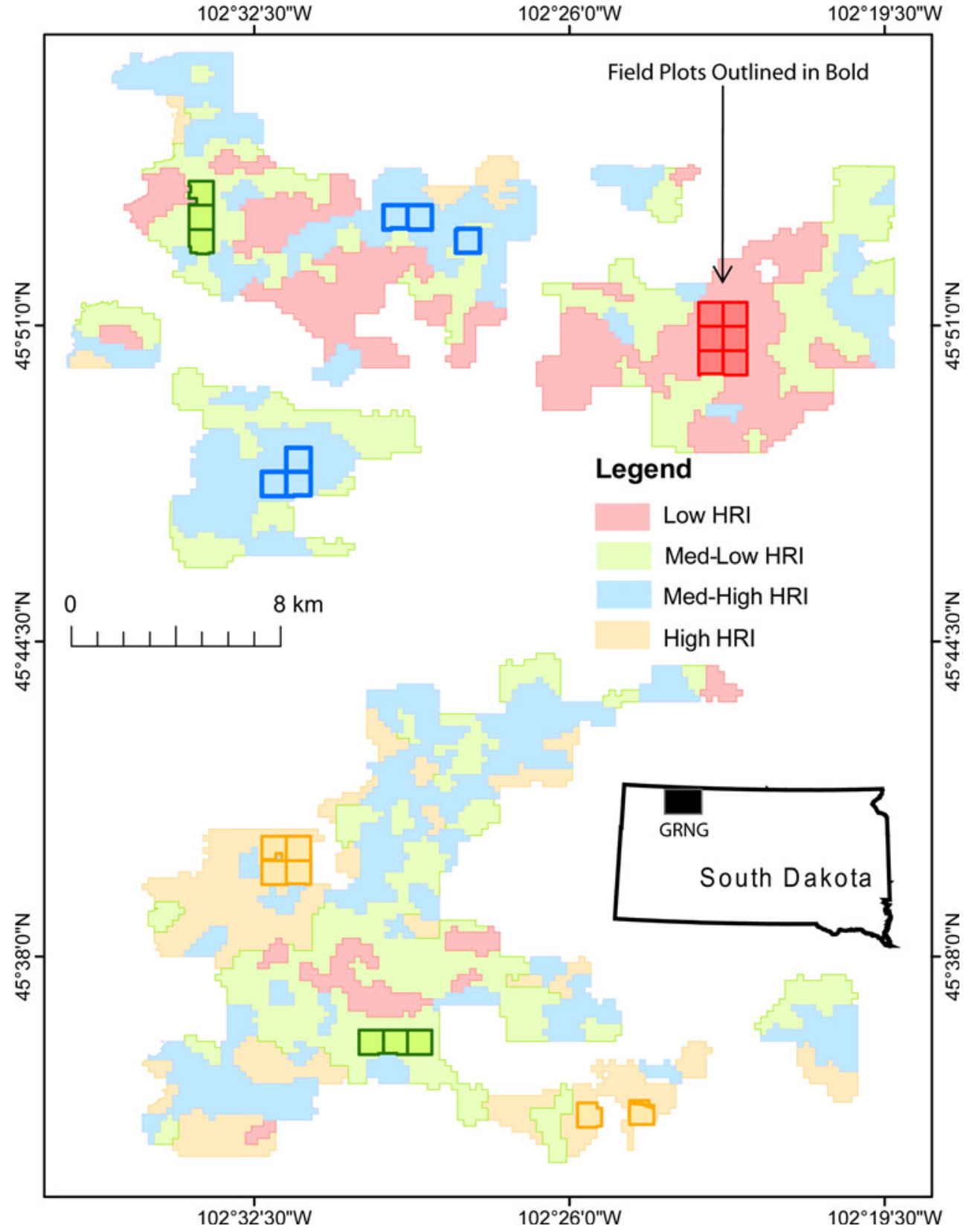


Table 1 Spectral data available from space-borne imaging spectrometers Landsat TM (http://ned.usgs.gov/) and the ASTER (http://www.science.aster.ersdac.or.jp/en/index.html) indicating spectral region and band width

\begin{tabular}{lllllll}
\hline Sensor & Blue & Green $(\mu \mathrm{m})$ & Red $(\mu \mathrm{m})$ & Near infrared $(\mu \mathrm{m})$ & Mid infrared & Short-wave infrared \\
\hline Landsat 5 & $0.45-0.52 \mu \mathrm{m}$ & $0.52-0.60$ & $0.63-0.69$ & $0.76-0.90$ & $1.55-1.75 \mu \mathrm{m}$ & $2.085-2.35 \mu \mathrm{m}$ \\
ASTER & Not available & $0.52-0.60$ & $0.63-0.69$ & $0.76-0.86$ & Not operational & Not operational \\
\hline
\end{tabular}

cattle (May-October), and stocking rates are approximately one animal unit per hectare. Federally-managed lands are fragmented by many privately-held enclaves, so the GRNG is not contiguous (Hansen 2008).

The region-of-interest for this project was initially defined as an approximately 100,000-ha tract of land located in the center of the GRNG (NE corner $45^{\circ} 56^{\prime} 2^{\prime \prime} \mathrm{N}, 102^{\circ} 10^{\prime} 35^{\prime \prime} \mathrm{W}$; $\mathrm{SW}$ corner $\left.45^{\circ} 33^{\prime} 12^{\prime \prime} \mathrm{N}, 102^{\circ} 34^{\prime} 58^{\prime \prime} \mathrm{W}\right)$. Included in this tract were herbaceous and non-herbaceous vegetation, roads, rivers, and buildings. To narrow the landscape to herbaceous grassland vegetation only, the tract was separated into herbaceous and non-herbaceous vegetation using an objectbased classification method applied to a Landsat 5 image (acquired July 10, 2008). Groundtruth consisted of known herbaceous vegetation field points geo-located by the USFS (Sjursen 2009). Six Landsat bands (between 0.45 and $2.35 \mu \mathrm{m}$ wavelengths; Table 1) were used to delineate polygons with similar spectral features (Benz and others 2004) using Definiens eCognition Developer (v.7) ${ }^{\circledR}$ objectbased classification software. A binary recursive classification and regression tree algorithm (Feldesman 2002) implemented in the $\mathrm{R}^{\circledR}$ statistical package (R Development Core Team 2009) was used to classify the polygons into herbaceous and non-herbaceous vegetation classes (Bittencourt and Clarke 2003). Only the herbaceous vegetation cover was of interest for this study, therefore non-herbaceous areas were removed. The classification resulted in 36,000 ha of USFS land area, which was used on all subsequent analyses (Fig. 1) and is herein referred to as our landscape-ofinterest (LOI).

To ensure we included a potentially wide range of canopy characteristics and reflectance values representative of our LOI, we evaluated the landscape for spatial trends in vegetation greenness (Huete and others 2002) over the last 10 years. The 16-day, Moderate Resolution Imaging Spectrometer (MODIS)-based, enhanced vegetation index (EVI) data for June and July from 2000 to 2009 were downloaded from the MODIS global subsets website (http://daac.ornl. gov/MODIS/modis.shtml). Forty images of EVI data were combined into one multi-temporal-band image, and an unsupervised classification was performed using ENVI/ IDL $^{\circledR}$ to identify those areas where EVI was consistently higher or lower than surrounding areas over the 10-year period. The classification yielded four historical reflectance index (HRI) groups, which accounted for $98 \%$ of the LOI
(Fig. 1): low historical reflectance (depicted as red), medium-low historical reflectance (depicted as green), mediumhigh historical reflectance (depicted as blue), and high historical reflectance (depicted as yellow). The HRI classification was then used to facilitate collection of field data representing a range of grassland canopy properties for this mixed-grass prairie landscape.

DEM data, 10-m pixel resolution, were accessed from the USGS National Elevation Dataset [http://ned.usgs.gov/ (Gesch and others 2002)]. We used the DEM to stratify the landscape into three topographic positions: summits, midslopes or toeslopes (Qin and others 2009). ArcGIS spatial analyst was used to generate the landform data from the DEM (Jenness 2006), and a neighborhood analysis $(8 \times 8$ pixel moving window $)$ was used to identify local maxima and minima locations and flow directions. Slope, aspect and curvature were calculated by fitting a quadratic surface to the DEM for an 80-m kernel size and taking the appropriate derivatives (MacMillan and others 2000; Wood 1996). A cluster tolerance of $70 \mathrm{~m}$ was used for the topographic zones because this was the minimum distance between summits, midslopes and toeslopes observed at our field-sites. The 80-m kernel size represented a buffered distance slightly longer than the observed $70 \mathrm{~m}$ minimum between positions.

We compared modeled topographic position with actual topographic position at our 72 field sites. Most $(90 \%)$ of the modeled summit, midslope and toeslope positions were correctly classified when compared with field-sites. Elevation data from the DEM were similar to elevation data collected with the GPS. The regression of elevation from DEM on measured elevation was linear $\left(r^{2}=0.97\right)$. Modeled topographic position polygons were used as input for subsequent landscape analyses. Delineation of summits, midslopes and toeslopes facilitated landscape analysis that included both image reflectance and topographic position. We layered modeled topographic position polygons (vector data) and image pixels located within each polygon (raster data). We found the average spectral index value for each topographic position polygon using only those pixels located completely within a polygon. Pixels crossing into more than one polygon and polygons $<1,000 \mathrm{~m}^{2}$ were not included. The resulting dataset included over 9,000 topographic position polygons, and each polygon was spatiallylinked to a spectral index value. 
Fig. 2 The field sampling design for collection of vegetation attributes associated with canopy structure. At each field plot, aboveground vegetation data were collected according to the figure inset at summit, mid and toeslope positions

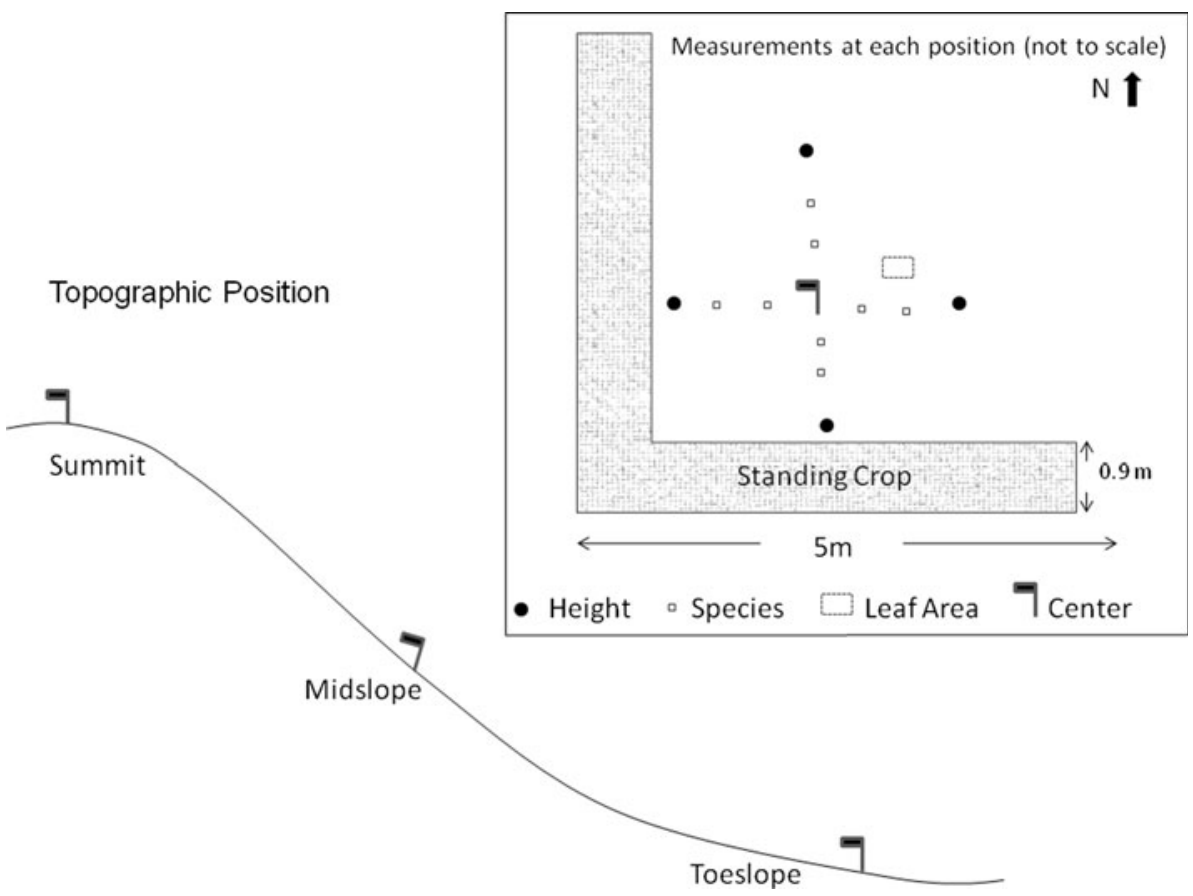

\section{Plot Selection and Field Data Collection}

Six field plots were randomly selected within each of the four color-coded HRI groups listed above and mapped in Fig. 1 using 1-km MODIS pixels. Sample plots were selected to be homogenous (no multiple HRI classes within a pixel) and to represent summit, midslopes and toeslope locations. This resulted in 18 points per HRI $(6$ plots $\times 3$ topographic positions). These random points (MODIS pixel centers) were generated in Arc Map and geo-located in the field (Dauwalter and others 2006) using a submeter, realtime, differential Trimble Geo XT Global Positioning System (GPS) and Beacon receiver (Trimble Navigation, Sunnyvale, CA). Those points that were not safely accessible with an all-terrain vehicle were removed and replaced with new points to achieve a total of six field-plots per category (Fig. 1). Accessibility was problematic for the low HRI areas (red), which is why the six plots border each other. From the center of each plot, the nearest south-facing slope was geo-located and logged using a GPS, along with summit, midslope and toeslope positions. We selected the nearest south facing slopes in order to minimize any effects of aspect and sun exposure variation on plant properties examined, so that observed differences in sampling locations could be attributed to topographic position and not aspect (Milchunas and others 1989). The shape file georeferencing specific topographic position within each plot was used for field data collection and for Landsat TM and ASTER data extraction. The range of elevations recorded at field sites was 740-850 m. Each position was flagged for subsequent sample collection (Fig. 2).
Functional land cover (FLC) groups were characterized at each of the 72 sites ( 24 plots $\times$ three positions) between 20 June and 15 July 2010 using Daubenmire frames (1959), which provide a method to visually estimate percent cover using a predetermined set of ranges. Frames $(0.5 \times 0.2 \mathrm{~m})$ were placed both 1 and $2 \mathrm{~m}$ from the center of the plot in the cardinal directions (Fig. 2). This resulted in a total of eight frames per site. We estimated species cover within each frame as either $<5 \%, 5-25 \%, 25-50 \%, 50-75 \%$, or greater than $75 \%$. Minor species representing $<5 \%$ of plant cover that could not be identified were logged as unknown vegetation. All species representing more than $5 \%$ of the canopy were identified. Average species cover was calculated using all eight frames at each site and each species was assigned to one of three FLC categories: forb, mid-grass or short-grass. Rocks and bare ground were assigned to a nonvegetation group and senescent vegetation was assigned to the litter group. Dominant and co-dominant species based on percent cover were identified for the four frames closest to center, and the four frames furthest from the center of the plot. Ecological site names (a soil-based classification system) were identified (http://soildatamart.nrcs.usda.gov/) and also listed for each of the 72 sites.

Both cattle grazing and fire occur on the GRNG, with variable fire locations, grazing intensities and cattle turnout dates by paddock. Small paddock sizes precluded specifically controlling for cattle use and fire in this study. Stocking rates in 2010 were similar among paddocks within our LOI. During the collection of field data in July (see below), cattle use was not evident for the high HRI (yellow) plots located at the south end of the LOI (Fig. 1), where cattle turn-out was delayed to 
mid-July. The high HRI plots were also located in areas with no history of tillage. We found evidence of recent fire at two of the medium-high HRI plots (blue) located at the north-center section of the LOI. The USFS confirmed that prescribed burns occurred at these two plots in April 2010. Inclusion of grazed, ungrazed, recently-burned, and unburned plots provided for collection of a full range of data representative of multiple stages of plant growth and development, as recommended for large landscapes (Luoto and others 2004) where assessments under realistic conditions are needed.

Standing crop mass (both green and total), leaf area (both green and total), unattached vegetation (litter), canopy height, $\mathrm{N}$ content, water content, and spectra from satellite-based sensors were collected at field plots during the week of both Landsat TM and ASTER flyovers (July 15-19, 2010). The Robel pole was used to measure canopy height at four points in the cardinal directions $4 \mathrm{~m}$ from flagged center (Fig. 2). A large L-shaped area $\left(10 \mathrm{~m}^{2}\right)$ was mowed to $2 \mathrm{~cm}$ height using a cycle-bar mower. This configuration was selected to incorporate spatial variability in standing crop biomass representative of the 15-m (ASTER) or 30-m (Landsat TM) pixels (Beeri and others 2007). Actual area mowed was recorded and total wet mass determined in the field with a Mettler-Toledo (SB32001-GA) scale (Mettler-Toledo, Columbus, OH). A sub-sample of mowed vegetation was retained for determination of dry mass in the laboratory. A $0.1 \mathrm{~m}^{2}$ frame was also placed northeast of the mowed area and materials collected for plant separation and laboratory analyses. Standing vegetation within the frame was clipped to $2 \mathrm{~cm}$ height and stored at $4{ }^{\circ} \mathrm{C}$. The standing material was separated into green or brown vegetation groups, leaf area measured with a LI-3100C Area Meter (LICOR Inc., Lincoln, Nebraska, USA), dried at $60{ }^{\circ} \mathrm{C}$, ground through a 1-mm mesh, and analyzed for total $\mathrm{N}$ using dry combustion on a Carlo Erba Model NA 1500 Series 2N/C/ $\mathrm{S}$ analyzer (CE Elantech, Lakewood, NJ).

Litter (unattached plant material) in the small frame was collected and dried at $60{ }^{\circ} \mathrm{C}$. All data are reported on a dry mass basis. The proportion of green material collected in the small frame was used to calculate the mass of green material in standing crop for the $10 \mathrm{~m}^{2}$ mowed areas (Beeri and others 2007). Small-frame data were used to determine the correlation between mass and leaf area and for canopy water content. Canopy water content was determined as the difference in mass before and after oven drying. Canopy $\mathrm{N}$ and water contents included both green and brown materials. Both mass and leaf area data are reported as total amounts and amounts for green vegetation only.

Remote Sensing-Based Data Acquisition and Processing

An ASTER Level 1B image collected on July 15, 2010 was downloaded from the ASTER data website. The Level 1B data were projected UTM Zone 13 North, WGS-84. Standard ASTER radiometric calibration and geometric correction coefficients were used for re-sampling (Fujisada 1998). The instrument digital numbers for the visible bands were converted to at-satellite radiance $\left(\mathrm{W} \mathrm{m}{ }^{-2} \mathrm{sr}^{-1} \mu \mathrm{m}^{-1}\right)$ for each channel using the gain and offset coefficients provided in Level 1B metadata (Tonooka and others 2003). The geometric data correction results were fine-tuned using a GPS with sub-meter resolution collected in the field and from road network vectors for the study area. The resulting ortho-rectified images were co-registered within 0.5 pixel root mean square error (RMSE).

A cloud-free Landsat TM image was collected on July 16, 2010 (http://glovis.usgs.gov/). We calibrated the Landsat raw radiometric data by applying Landsat datespecific instrument calibration parameter files (Markham and Barker 1987) converting 8-bit satellite-quantized calibrated digital numbers (DN) into top of the atmosphere (TOA) reflectance. These data were converted to TOA:

$L_{\mathrm{sat}}=(\mathrm{DN}-B) / G$

where $L_{\mathrm{sat}}$ is the band-specific TOA radiance $\left(\mathrm{W} \mathrm{m} \mathrm{m}^{-2} \mathrm{sr}^{-1}\right.$ $\mu \mathrm{m}^{-1}$ ), DN is the satellite quantized calibrated digital number, $B$ is the band-specific bias in DN from Landsat calibration parameter files, and $G$ is the band-specific gain $\left(\mathrm{m}^{2} \mathrm{sr} \mu \mathrm{m} \mathrm{W}^{-1}\right)$ from Landsat calibration parameter files. We then converted the radiance data into at-satellite reflectance using:

$\rho_{\mathrm{ASR}}=\frac{\left(\pi \times L_{\mathrm{sat}}\right)}{\left(E_{0} \times \cos (\Theta)\right)}$

where $\rho_{\mathrm{ASR}}$ is the band-specific at-satellite reflectance, $E_{0}$ is the exoatmospheric solar constant $\left(\mathrm{W} \mathrm{m}^{-2} \mu \mathrm{m}^{-1}\right)$ corrected for solar distance, and $\Theta$ is the solar zenith angle.

NDVI and SR71 spectral indices were calculated using reflectance data scaled between 0 and 1 .

$\mathrm{NDVI}=\left(\rho_{\mathrm{NIR}}-\rho_{\mathrm{Red}}\right) /\left(\rho_{\mathrm{NIR}}+\rho_{\mathrm{Red}}\right)$

SR71 $=\left(\rho_{\text {Mid-IR }}\right) /\left(\rho_{\text {Blue }}\right)$

where $\rho_{\text {Red }}, \rho_{\mathrm{NIR}}, \rho_{\mathrm{Blue}}$, and $\rho_{\text {Mid-IR }}$ are surface reflectances in red, near infrared, blue and mid infrared portions of the electromagnetic spectrum (Huete and others 2002).

\section{Statistical Analyses}

Field Site Characteristics, Reflectance, and Topographic Position

Vegetation data were analyzed by fitting a generalized linear mixed model (SAS System for Windows, copyright $(\mathrm{C}$ 2002-2008, SAS Institute Inc., Cary, NC, USA). The model fixed effects included topographic position, HRI group, and 
the interaction of topographic position and HRI group, and random effects included plot and plot $\mathrm{x}$ topographic position. A Tukey-Kramer test was used to determine if least-square mean values at specific topographic positions or specific HRI groups were significantly different from each other. Measured percent cover for each of the five FLCs (rock/bare soil, litter, forb, short-grass, mid-grass) were fitted statistically to a beta distribution because these categorical data were not normally distributed. Green standing crop $\left(\mathrm{kg} \mathrm{ha}^{-1}\right)$, total standing crop $\left(\mathrm{kg} \mathrm{ha}^{-1}\right)$, green leaf area $\left(\mathrm{cm}^{2} \mathrm{~cm}^{-2}\right)$, total leaf area $\left(\mathrm{cm}^{2} \mathrm{~cm}^{-2}\right)$, unattached litter $\left(\mathrm{kg} \mathrm{ha}^{-1}\right)$ canopy $\mathrm{N}$ mass $\left(\mathrm{kg} \mathrm{ha}^{-1}\right)$, canopy water content $\left(\mathrm{kg} \mathrm{ha}^{-1}\right)$, canopy height $(\mathrm{cm})$, Landsat-NDVI, ASTER-NDVI, and LandsatSR71 data were normally distributed and were analyzed separately using the same mixed model. Total and green leaf areas were modeled as functions of total and green standing crop using the small frame data to establish predictive equations for leaf area. Standing crop mass data collected from the large "L"-shaped area (Fig. 2) were used in all statistical analyses and were regressed on canopy height (Uresk and Benson 2007; Vermiere and others 2002). Spectral VI data were also analyzed to determine which spectral index correlated most highly (highest $r^{2}$ ) with canopy height.

\section{Landscape Reflectance and Topographic Position}

Similar analyses were performed to determine relationships between topographic position and spectral VIs for the entire LOI. We tested for the fixed effects of topographic position, HRI group, and the topographic position $x$ HRI group interaction on the spectral VI and sensor most highly correlated with canopy height. This step was also performed on Landsat and ASTER-NDVI data to evaluate if the influence of topographic position on NDVI was evident at both field-site and landscape scales. Statistical significance was set at $P<0.05$.

\section{Results}

\section{Field Site Percent Cover}

Percent cover per unit area $(\%)$ by FLC did not vary with HRI group but did vary with topographic position for the rock/bare soil $\left(F_{2,40}=3.91 ; \quad P<0.05\right)$, short-grass $\left(F_{2,40}=12.15 ; \quad P<0.0001\right), \quad$ and mid-grass $\left(F_{2,40}=\right.$ 39.25; $P<0.0001)$. Percent cover per unit area for forbs and litter did not vary with topographic position. Summit mid-grass percent cover was significantly lower than that at mid and toeslope positions. Average [ \pm standard error (se)] mid-grass percent cover increased from summit (9 $\pm 1 \%)$, to midslope $(21 \pm 2 \%)$, to toeslope (29 \pm $2 \%$ ) positions. Average rock/bare soil at summit (22 \pm
$2 \%)$ and midslope positions $(14 \pm 2 \%)$ tended to be greater than rock/bare soil cover for the toeslope position $(9 \pm 2 \%)$. Average short-grass percent cover was greatest at the summit $(35 \pm 2 \%)$ and lowest at the toeslope $(20 \pm 2 \%)$. However, short-grass percent cover at the toeslopes for the high HRI group (yellow) was approximately $15 \%$ greater than short-grass cover for the other HRI groups, likely due to the lack of tillage history at the south end of the GRNG. The test for effects of HRI group by topographic position on short-grass cover indicated the interaction was significant $\left(F_{6,40}=3.90 ; P<0.01\right)$. Litter and forb cover, however, varied little with topographic position and averaged $20 \%( \pm 4)$ and $17 \%( \pm 3 \%)$ across all field sties, respectively.

An average of five species was inventoried at all 72 field sites, regardless of topographic position (Table 2). The predominance of short-grasses such as $B$. gracilis at the summits and mid-grasses such as A. cristatum at the toeslopes are evident in both species occurrence data (Table 2) and percent cover data (Fig. 3). Ecological site data were mapped to characterize selected plot soil characteristics (NRCS 2011). These ranged from sandy to clayey, and most were classified as silty across all landscape categories (Table 3).

Field Site Standing Crop, Leaf Area, N, Water, and Height

Measured vegetation properties varied significantly with topographic position, including green standing crop $\left(F_{2,40}=8.91 ; P<0.001\right)$, total standing crop $\left(F_{2,40}=\right.$ 4.32; $P<0.05)$, green leaf area $\left(F_{2,40}=9.68 ; P<0.001\right)$, total leaf area $\left(F_{2,40}=15.05 ; P<0.0001\right)$, canopy $\mathrm{N}$ mass $\left(F_{2,40}=23.66 ; P<0.0001\right)$, canopy water $\left(F_{2,40}=11.25\right.$; $P<0.0001)$, and canopy height $\left(F_{2,40}=26.22 ; P<\right.$ $0.0001)$. These did not vary with HRI group, which indicated the effects of topographic position on these variables were similar within our herbaceous vegetation LOI. Clear topographic position trends for leaf area and standing crop (total and green material only) are illustrated in Fig. 4a, b and parallel trends in canopy $\mathrm{N}$ mass, water content and height (data not shown). Highest average $( \pm$ se) value for canopy $\mathrm{N}$ at toeslope ( $\left.36 \pm 3 \mathrm{~kg} \mathrm{ha}^{-1}\right)$, was followed by midslope $\left(26 \pm 2 \mathrm{~kg} \mathrm{ha}^{-1}\right)$ and summit $\left(18 \pm 2 \mathrm{~kg} \mathrm{ha}^{-1}\right)$. Average water content at toeslope (924 $\left.\pm 63 \mathrm{~kg} \mathrm{ha}^{-1}\right)$ was significantly greater than midslope $\left(723 \pm 66 \mathrm{~kg} \mathrm{ha}^{-1}\right)$ and summit $\left(579 \pm 68 \mathrm{~kg} \mathrm{ha}^{-1}\right)$ positions. Similarly, average canopy height at toeslope $(15 \pm 1 \mathrm{~cm})$ and midslope $(13 \pm 1 \mathrm{~cm})$ was significantly greater than at summit $(8 \pm 1 \mathrm{~cm})$. Summit average height was lower than the previously established threshold value of $9 \mathrm{~cm}$, whereas average height at the mid and toeslope positions exceeded this threshold (Fig. 5a). Canopy height, however, was 


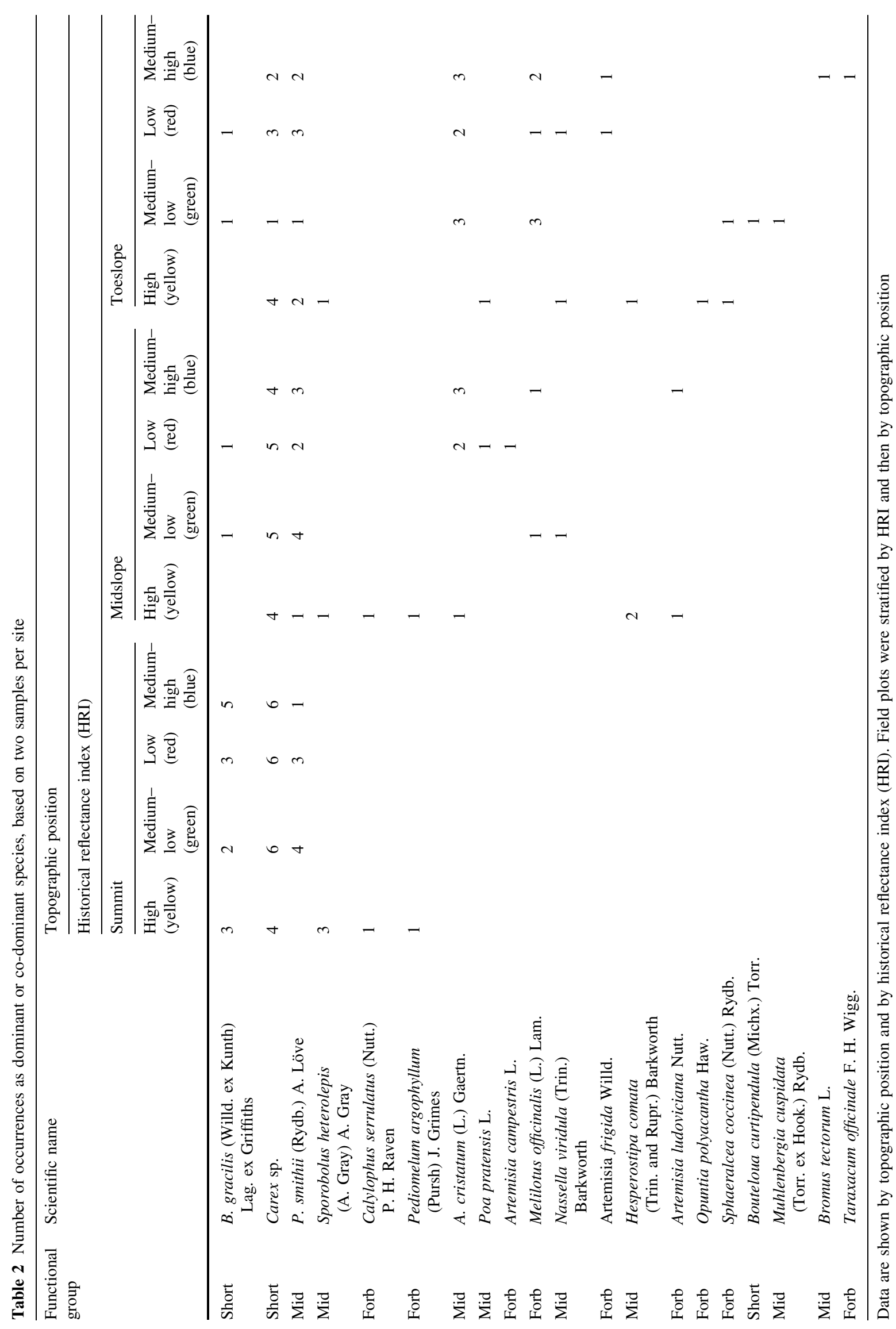




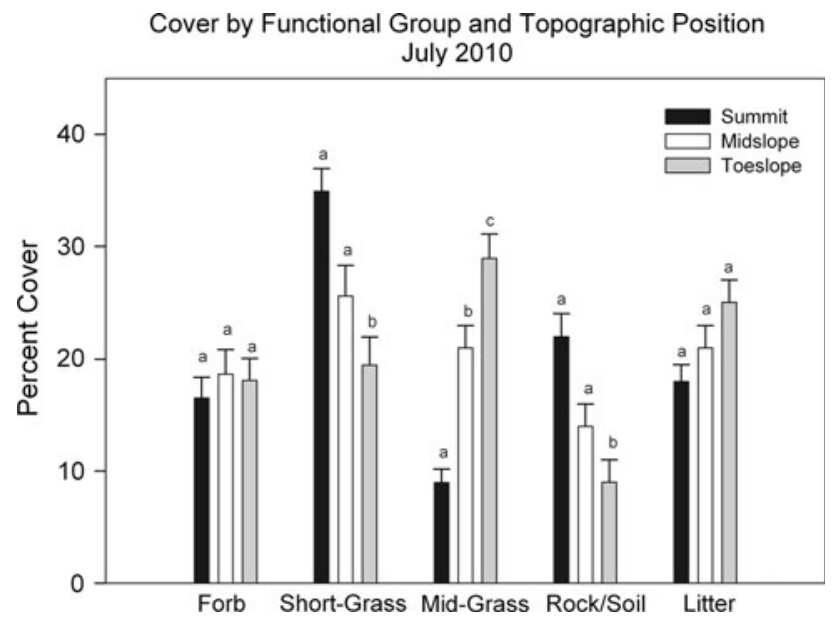

Fig. 3 Average ( \pm standard error) percent cover by group, including rock/bare soil and senescent vegetation classified as litter. Letters above error bars denote those groups that varied significantly with topographic position

also marginally affected by HRI group $\left(F_{2,40}=3.70\right.$; $P=0.051$ ). Canopy height for the high HRI (yellow) tended to be higher than the other HRI groups (Fig. 5a) possibly because cattle had not yet visited these plots prior to our field sampling. The topographic position by HRI group interaction was not significant. Average amount of litter at summit was $234( \pm 92)$, at midslope was 583 $( \pm 156)$, and at toeslope was $554( \pm 138)$, and these were not significantly different.

The linear regressions of total leaf area (TLA) and green leaf area (GLA) on standing crop mass $\left(\mathrm{kg} \mathrm{ha}^{-1}\right)$ yielded the following predictive equations:

$\begin{array}{ll}\mathrm{TLA} & =0.1424+0.0004 \times \mathrm{TSC} ; \quad r^{2}=0.85 \\ \mathrm{GLA} & =0.1408+0.0003 \times \mathrm{GSC} ; \quad r^{2}=0.79\end{array}$

The best relationship between total standing crop (TSC) and canopy height was fitted with a quadratic polynomial (Fig. 6):

TSC $=-53+129 \times$ height $+2 \times$ height $^{2} ; \quad r^{2}=0.65$

Field Site and Landscape Reflectance

NDVI pixel values varied significantly with topographic position for both Landsat TM $\left(F_{2,40}=37.62 ; P<0.0001\right)$ and ASTER $\left(F_{2,40}=28.10 ; P<0.0001\right)$ but not with HRI group (Fig. 7a). Average NDVI ( \pm se) for Landsat ranged from $0.24( \pm 0.01)$ at summits to $0.33( \pm 0.01)$ at toeslopes, while ASTER average NDVI ranged from $0.11( \pm 0.01)$ at summits to $0.20( \pm 0.01)$ at toeslopes. Field site values for NDVI ranged from 0.20 to 0.45 for Landsat and from 0.07 to 0.29 for ASTER. NDVI was weakly correlated with

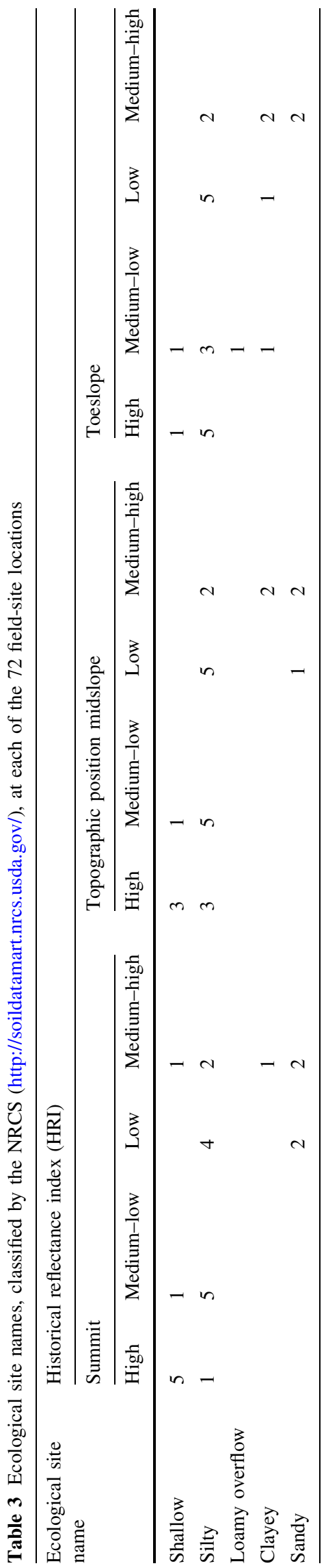



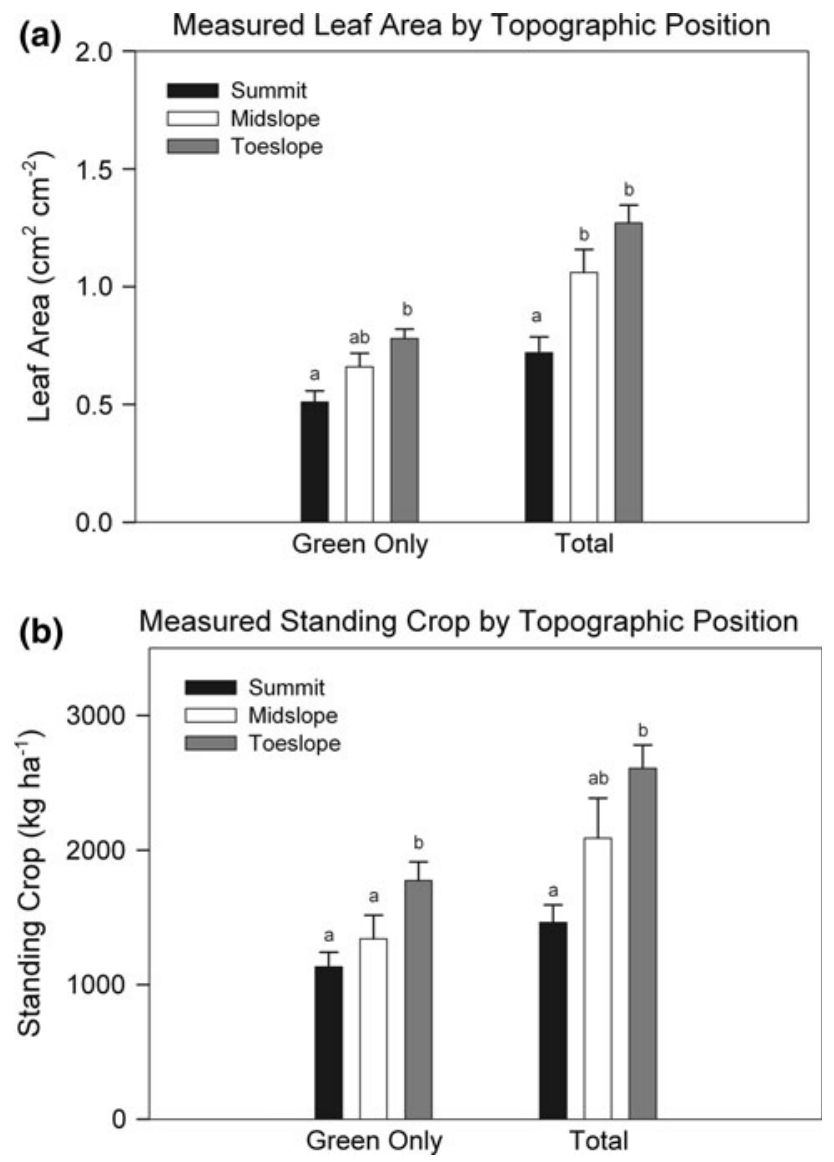

Fig. 4 a Average ( \pm standard error) leaf area for green material only and for total leaf area by topographic position; b standing crop biomass for green material and total standing crop. Letters above error bars denote significant differences among topographic positions

canopy height measured at the field sites $\left(r^{2}<0.28\right)$. Landscape statistics performed on NDVI values calculated for each modeled elevation polygon in our LOI indicated both Landsat $\left(F_{2,9509}=772.55 ; P<0.0001\right)$ and ASTER $\left(F_{2,11003}=849.69 ; P<0.0001\right)$ varied significantly with topographic position and not HRI group (Fig. 7b). Landsat average NDVI for the LOI ranged from $0.28( \pm 0.01)$ at summits to $0.33( \pm 0.01)$ at toeslopes, while ASTER average NDVI ranged from $0.15( \pm 0.01)$ at summits to $0.21( \pm 0.01)$ at toeslopes. Summit values for Landsat and ASTER-NDVI at both field-site and landscape scales were significantly lower than their counterparts at mid and toeslope positions.

Similar to NDVI, SR71 pixel values from Landsat also varied significantly with topographic position for $\left(F_{2,40}=20.36 ; P<0.0001\right)$. Like NDVI, SR71 was not affected by HRI class. However, there was an inverse relationship between canopy height and SR71, with highest SR71 values at summits (Fig. 8). Average field-site SR71 ranged from $0.80 \pm 0.01$ at summits to $0.73 \pm 0.01$ at toeslopes (Fig. 5a). Individual site SR71 ranged from 0.45
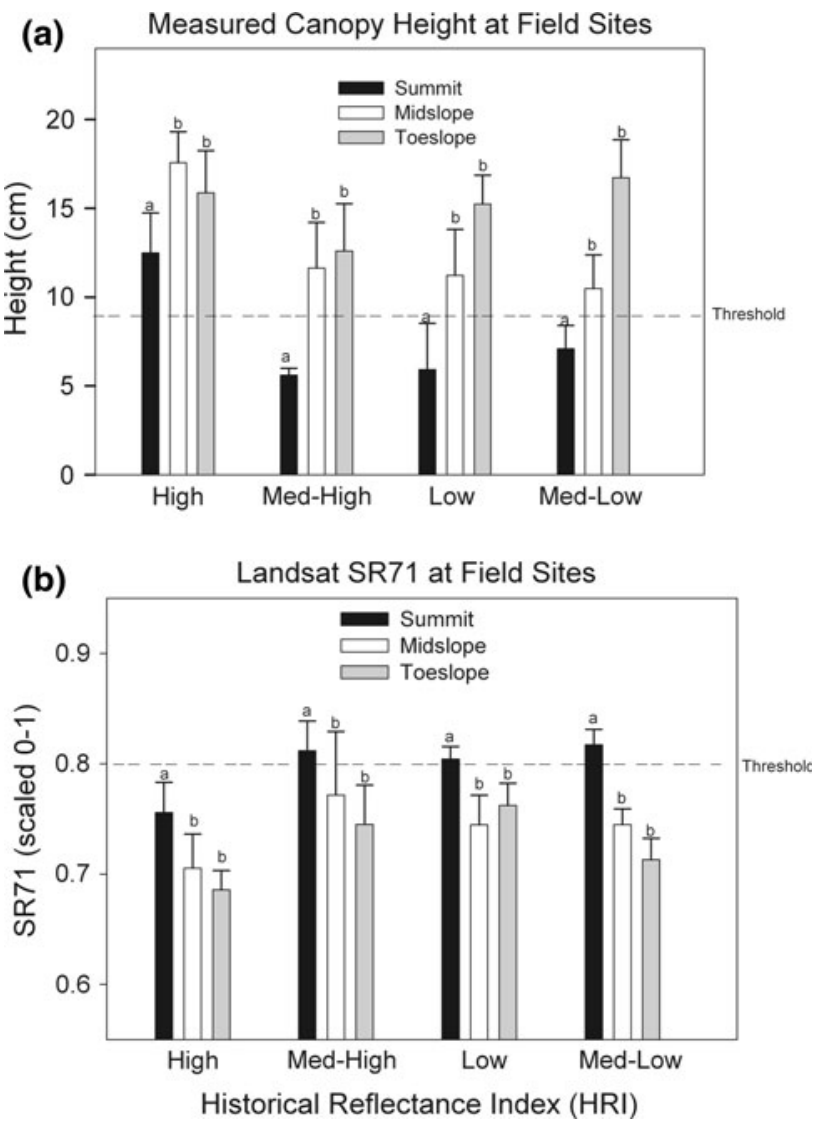

Fig. 5 a Canopy height average ( \pm standard error) by HRI group and topographic position. The $9 \mathrm{~cm}$ height threshold is indicated by the broken line for reference; b Landsat SR71 by HRI group and topographic position. Average summit SR71 value is indicated by the broken line for reference. Letters above error bars denote significant differences among topographic positions

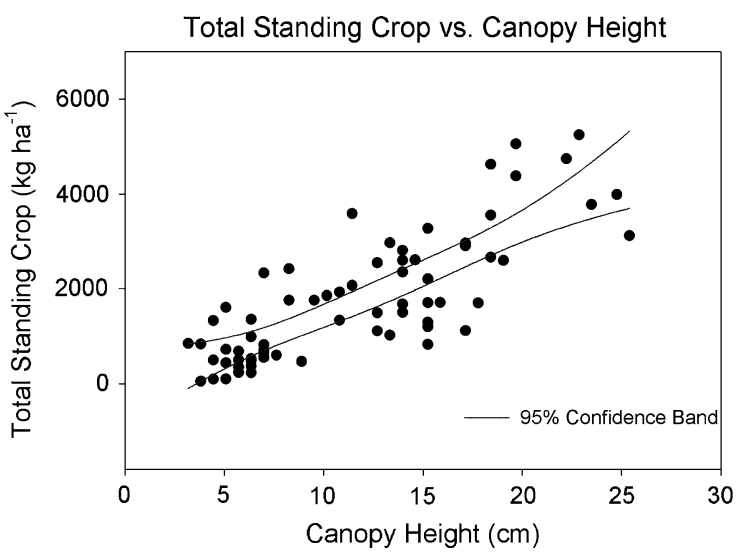

Fig. 6 Total standing crop biomass versus canopy height measured at 72 sites, July 2010

to 0.90 . Similar to data collected on the ground, the best relationship between Landsat SR71 and canopy height was fitted with a quadratic polynomial (Fig. 8): 

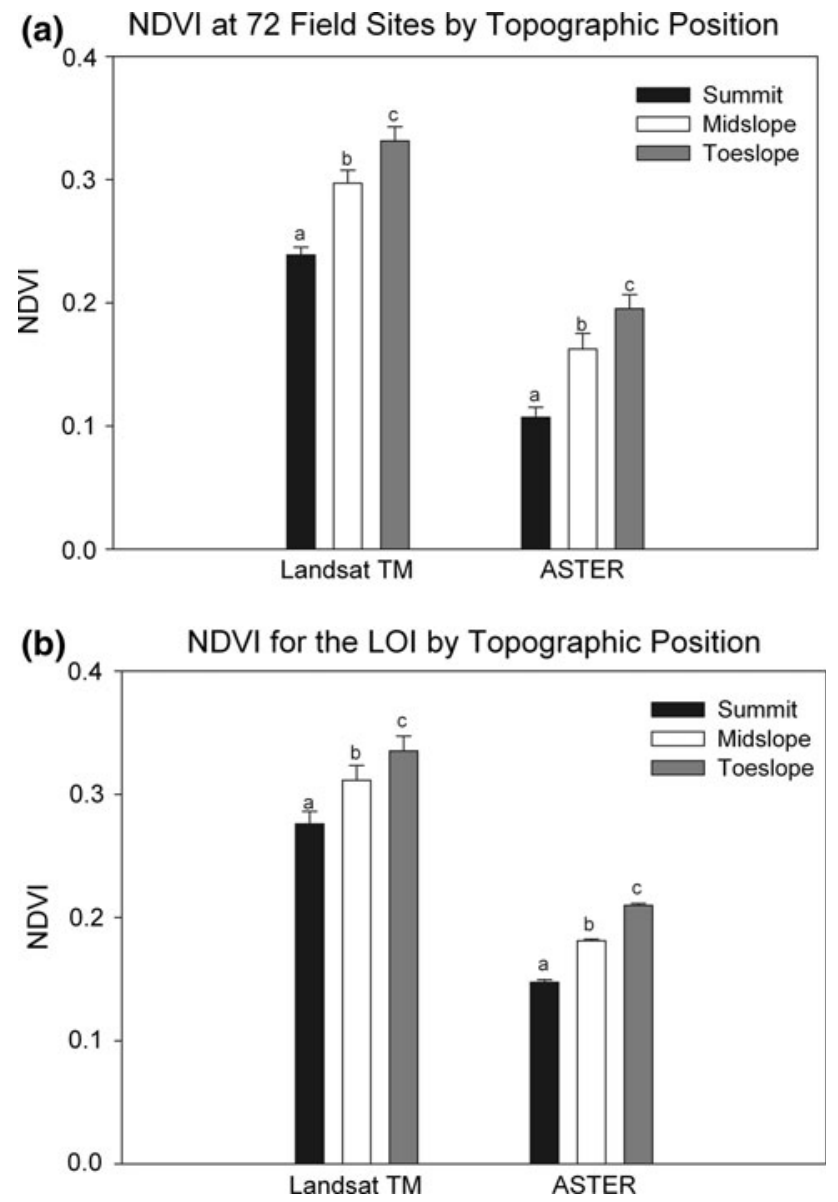

Fig. 7 a NDVI average ( \pm standard error) collected by Landsat (July 16, 2010) and ASTER (July 15, 2010) sensors for 72 field sites by topographic position; b NDVI average ( \pm standard error) collected by Landsat (July 16, 2010) and ASTER (July 15, 2010) sensors for the LOI by modeled elevation polygon. Letters above error bars denote significant differences among topographic positions

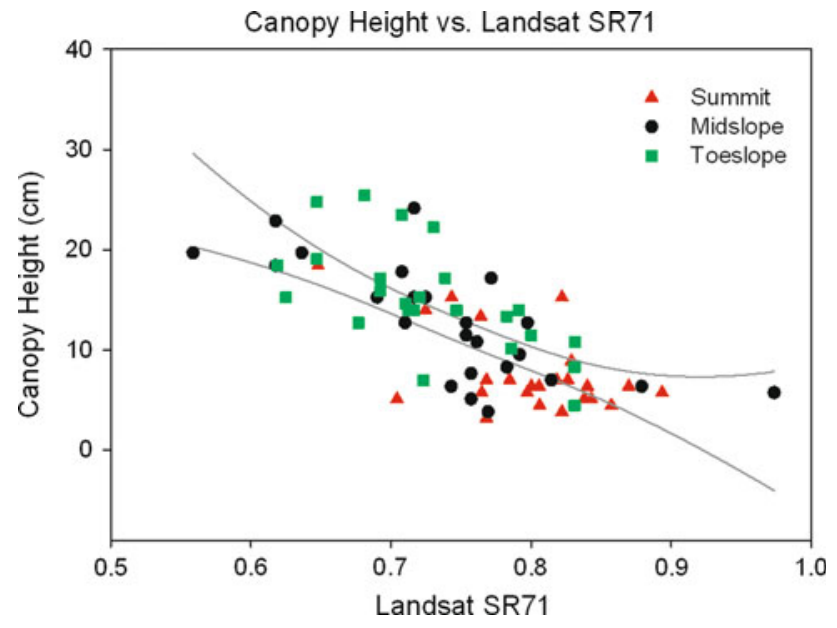

Fig. 8 Canopy height measured using the Robel pole versus Landsat SR71 index collected at 72 field sites for each topographic position group. The $95 \%$ confidence bands are the lines shown in grey. Image data were acquired July 16, 2010
Height $=87-144 \times$ Landsat SR71 $+58 \times$ Landsat SR71 $^{2}$;

$$
r^{2}=0.53
$$

Landscape application of SR71 indicated higher average SR71 values were consistently found at summits $(0.74 \pm 0.01)$, followed by midslope $(0.70 \pm 0.01)$ and then toeslope $(0.68 \pm 0.01)$ position groups (Fig. 5b). However, average SR71 values for the high HRI group (yellow) were lower than all other HRIs at all positions. These results collected over the entire LOI mirrored the SR71 pixel data collected at field-sites (Fig. 5b). This trend for lower SR71 values for the high HRI group (where canopy height was greater) was similar to trends for greater heights observed in the field for this HRI (Fig. 5a).

The Landsat SR71 index correlated with canopy height better than NDVI, with higher values at summits than at mid and toeslopes. We identified 29 sites where canopy height was below the $9 \mathrm{~cm}$ management threshold. Eighteen of these low structure sites were located at summits, ten at midslopes and one at a toeslope. Average Landsat SR71 collected at these sites was 0.8 , which we used as a canopy height threshold. Sites where SR71 $<0.8$ represented areas where structure exceeded the minimum value. At the remaining 43 sites, SR71 was $<0.8$ and canopy height exceeded $9 \mathrm{~cm}$ at 40 sites. For NDVI, the 29 sites below $9 \mathrm{~cm}$ averaged 0.27 , and NDVI values $<0.27$ were considered potential areas of low structure. NDVI values for the 43 sites where height exceeded $9 \mathrm{~cm}$ were expected to be $>0.27$, but NDVI was $>0.27$ at only 31 of the 43 sites. We mapped SR71 values for July 16, 2010 (Fig. 9) to illustrate large-scale approximation of areas low in structure. The elevation drape illustrates low-lying areas that were below the threshold in July 2010, such as the area to the east that was burned and the area to the south that was fallowed (Fig. 9).

\section{Discussion}

We aimed to develop a grassland assessment method for a 36,000 ha landscape using Landsat, DEM and canopy structure data, where structure included plant FLC group, height, standing crop mass, leaf area, $\mathrm{N}$ mass, and water content. To this end, we tested the hypothesis that grassland canopy structure at summit positions are significantly different from mid and toeslope positions. We found summits were lower in all of these structural attributes, as compared to mid and toeslope positions. Accordingly, we found significantly lower values at summits for NDVI and higher values for SR71. A threshold value for SR71 (0.8) was established, where sites below than this value were considered above the structural management minimum. 


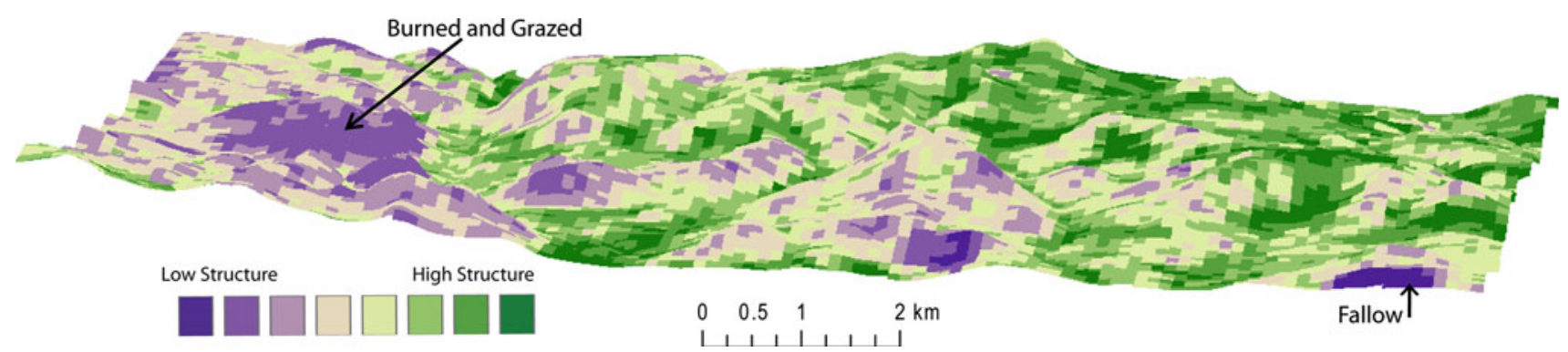

Fig. 9 Subset of the LOI where low-structure pixels below the Landsat SR71 index threshold are delineated in purple, as compared to pixels above the index threshold delineated in green on July 16,

Conversely, sites where SR71 exceeded this value represented areas where structural attributes were considered below the management minimum. This method supported comprehensive assessment of the GRNG with respect to grassland canopy structure, where specific areas below the threshold could be highlighted in a single image (Fig. 9).

Fundamental to grassland canopy management is biomass production, which is regulated by precipitation and topography (Knapp and others 1993). At the GRNG in $2010,28 \mathrm{~cm}$ of rainfall ( $80 \%$ of the annual average) occurred prior to the mid-July field sampling [North Dakota Agricultural Weather Network (NDAWN) 2000]. Therefore, standing crop and leaf area reported in 2010 were likely above average, although they are within the range reported at other North Dakota mixed-grass prairie ecosystem sites (Biodini and Manske 1996; Frank and Dugas 2001). We report only 1 year of data, but previous long-term studies have shown that structure at summits is consistently lower than at toeslopes (Knapp and others 1993; Milchunas and others 1989; Singh and others 1998). Both Milchunas and others (1989) and Knapp and others (1993) also found vegetation canopy characteristics were lower at summits and higher at toeslopes. Shortgrass prairie summits were lower than toeslopes with respect to aboveground net primary production (Milchunas and Lauenroth 1993), plant density and cover (Milchunas and others 1989), and root and crown biomass (Milchunas and others 1989), and soil organic matter (Burke and others 1999). Tallgrass prairie summits were lower in canopy $\mathrm{N}$, canopy water and net primary production, as compared to lowlands (Knapp and others 1993). Knapp and others (1993) concluded that topographic position was an important predictor of tallgrass ecosystem productivity, and we found similar relationships for mixed-grass prairie.

Comprehensive assessment of our 36,000-ha LOI required a different experimental design and alternative data collection methods than previous Robel pole studies (Benkobi and others 2000; Robel and others 1970; Uresk and Benson 2007; Uresk and Juntti 2008; Vermiere and others 2002). We needed to collect standing crop biomass at
2010. The elevation drape illustrates effects of topography on lowstructure pixels. The area to the west was burned in April 2010 and grazed by cattle in July

a scale representative of the variability within a large pixel, since our primary aim was to correlate canopy structural attributes and pixel data rather than canopy height and standing crop (Beeri and others 2007). Further, we aimed to detect natural variation in canopy structure for $30 \mathrm{~m}$ pixels, while others averaged multiple Robel pole readings collected along $200 \mathrm{~m}$ transects (Uresk and Benson 2007; Vermiere and others 2002). Consequently, our regression of standing crop on height was not as strong as reported by others (Uresk and Benson 2007). Better relationships between height and biomass were obtained when homogenous stands of vegetation were used (Robel and others 1970), where transects were stratified into high, medium or low structure groups (Benkobi and others 2000; Uresk and Benson 2007; Uresk and Juntti 2008), and where shortgrass, mixed-grass, and tallgrass prairie were compared (Vermiere and others 2002). Our random points typically comprised multiple species (Table 2), and species mixtures changed dramatically with topographic position (Fig. 3).

Landscape features limited the range of possible remote sensing-based data sources used in this study. For example, we needed to assess 36,000 ha of area, but important natural variation in structure occurred within a $70 \mathrm{~m}$ distance. Consequently, we applied medium-resolution satellite data ( $\leq 30-\mathrm{m}$ pixel size), where swath widths were $60 \mathrm{~km}$ (ASTER) and $185 \mathrm{~km}$ (Landsat TM). Working with 10- to 30-m pixel data required that we categorically analyze only three topographic positions, as compared to running transects along a toposequence and evaluating structure at multiple elevations. Advanced, high spatial-resolution $(<3 \mathrm{~m})$ data acquisitions for DEM and spectral reflectance could be tasked if finer-scale landscape models are needed. In these cases, acquisition and data processing costs for airborne sensor data could limit comprehensive spatial assessment to only a subset of the LOI.

Medium spatial resolution reflectance data from Landsat represent multiple canopy features (e.g., $\mathrm{N}$ mass and water content, plant architecture, and soil background), so spectra-based grassland models are often ecosystem-specific. Different spectral indices will apply for ecosystems where 
bare soil cover is high (Qi and others 1994), such as in the arid southwestern US (Holifield Collins and others 2008; Marsett and others 2006). Here, we measured multiple mixed-grass prairie canopy attributes known to influence spectra and found distinct patterns in land cover with topography but not soil series (Table 3). While SR71 provided an indication of areas relatively lower in structure, we did not attempt to tease apart these variables, in part because the Landsat data are spectrally and spatially too coarse for this heterogeneous grassland. We focused on relative differences in canopy structure that follow the topographic gradient for this ecosystem. Knowledge of these differences in conjunction with spectral VIs can assist managers identify canopies below management thresholds at landscape scales.

Data collected at the pixel scale for NDVI indicated strong effects of topography on NDVI, and this was corroborated by the full LOI analysis (Fig. 7). Figure 7 suggests that our sampling design provided a reasonable representation of the landscape. However, our thresholdbased approach to canopy structure using NDVI did not identify areas low in structure as well as the SR71. While SR71 was most highly correlated with canopy height, observed scatter (Fig. 6) precludes application of this tool as a quantitative measure.

Instead, the SR71 provided a broad-scale indicator of areas that may be below the minimum height (Figs. 9, 10). The above- versus below-threshold approach is limited to addressing the yes or no question "Is this area above the management threshold?" In this study, 3 of 43 sites were incorrectly classified as low structure when they were actually above the minimum value. This may have been due to the $30 \mathrm{~m}$ Landsat pixel size, where data were collected outside of the measurement area (Fig. 2). Better representation of mixed-grass prairie canopies using imagery may be achieved by collecting a greater number of canopy height measurements within a pixel.

The addition of topography to spectral index analyses highlights inherent landscape variability with the potential to complement grassland assessment methodologies. Larger differences in index values between summits and toeslopes over the landscape would suggest greater standing crop and structure. Conversely, if summit and toeslope index values were similar, standing crop and structure may be compromised and adaptive management needed. Each image should be evaluated with modeled DEM and field data to determine the index and threshold value that best represents landscape variation in structure. Continued application of topographic, field, and spectral index data could be refined to assist managers more comprehensively identify areas potentially low in structure (Fig. 10) and adapt to annual variations in grassland production.

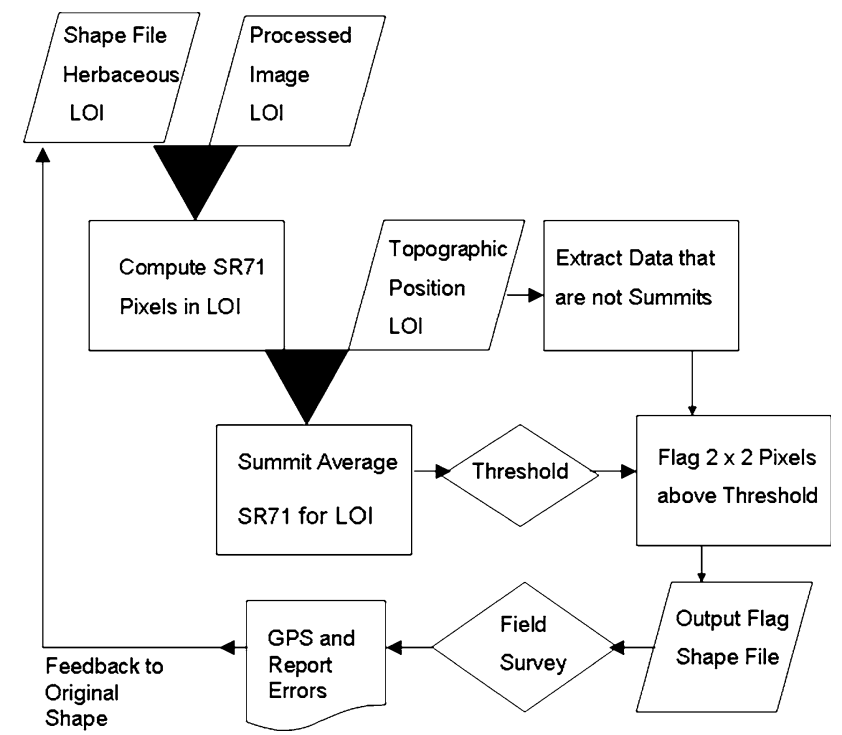

Fig. 10 Suggested data inputs and data processing steps for application of imagery and DEM for large-scale ecosystem assessment

\section{Conclusion}

We conclude that grassland structure varies with topographic position, and that comprehensive grassland assessment should include both topography and spectral VI layers. Here, we defined canopy structure as a combination of FLC group, standing crop mass, canopy height, leaf area, $\mathrm{N}$ mass, and water content, since spectral reflectance is influenced by all of these features. We suggest reflectance values at toeslopes that are similar to summits are likely low in structure, and these anomalies may be due to management (fire, grazing) or to other factors limiting plant productivity. Management adaptation would be needed where biological potential for structure or productivity cannot be met (Fig. 10). Grassland assessment in July (using this threshold-based approach) would facilitate landscape evaluation among stakeholders, when management adjustments are feasible and inherent limitations to plant productivity (e.g., disease, pests, and soil erosion) are readily apparent. Managers may find these comprehensive data will also advance understanding of these large landscapes by delineating subtle variations in livestock or wildlife habitat (Fig. 9), such as habitat heterogeneity. Continued application of archived and current SR71 and NDVI indices in conjunction with field and topographic data could help bridge the gap between climatic variation and grassland productivity. Finally, expanding this research to include finer-scale, hyperspectral data could improve the predictive power of spectra to estimate key grassland structural variables.

Acknowledgments This work would not have been possible without the gracious cooperation of GRNG Field Crew and Dakota Prairie 
Grasslands managers (Phil Sjursen, Dan Svingen, and staff at the Lemmon, SD field office). The authors heartily thank data collectors Justin Feld, Jonathan Rolfson, Sarah Waldron, Cari Ficken, Marla Striped-Face Collins, Mary Kay Tokach for their outstanding teamwork and attention to data quality. Special thanks to Cari Ficken, Duane Pool, Nick Saliendra, Brad Rundquist, and the anonymous reviewers for their comments. Support for this project was funded by the USFS Co-operative Agreement No. 5445-21310-001-07.

Disclosure Mention of trade names or commercial products in this publication is solely for the purpose of providing specific information and does not imply recommendation or endorsement by the US Department of Agriculture. USDA is an equal opportunity provider and employer

\section{References}

Beeri O, Phillips P, Carson P, Liebig M (2005) Alternate satellite models for estimation of sugar beet residue nitrogen credit. Agriculture, Ecosystems and Environment 107:21-25

Beeri O, Phillips R, Hendrickson J, Frank AB, Kronberg S (2007) Estimating forage quantity and quality using aerial hyperspectral imagery for northern mixed-grass prairie. Remote Sensing of Environment 110(2):216-225

Benkobi L, Uresk DW, Schenbeck C, King RM (2000) Protocol for monitoring standing crop in grasslands using visual obstruction. Journal of Range Management 53:627-633

Benz UC, Hofmann P, Willhauck G, Lingenfelder I, Heynen M (2004) Multi-resolution, object-oriented fuzzy analysis of remote sensing data for GIS-ready information. ISPRS Journal of Photogrammetry and Remote Sensing 58(3-4):239-258

Biodini ME, Manske L (1996) Grazing frequency and ecosystem processes in a northern mixed grass prairie, USA. Ecological Applications 6:239-256

Bittencourt HR, Clarke RT (2003) Logistic discrimination between classes with nearly equal spectral response in high dimensionality. In: IEEE international geoscience and remote sensing symposium, Toulouse, France, pp 3748-3750

Burke IC, Lauenroth WK, Riggle R, Brannen P, Madigan R, Beard S (1999) Spatial variability of soil properties in the shortgrass steppe: the relative importance of topography, grazing, microsite, and plant species in controlling spatial patterns. Ecosystems 2:422-438

Ceccato P, Gobron N, Flasse S, Pinty B, Tarantola S (2002) Designing a spectral index to estimate vegetation water content from remote sensing data: Part 1 . Theoretical approach. Remote Sensing of Environment 82:188-197

Chen JM (1996) Canopy architecture and remote sensing of the fraction of photosynthetically active radiation absorbed by boreal conifer forests. IEEE Transactions on Geoscience and Remote Sensing 34(6):1353-1368

Daubenmire R (1959) A canopy-coverage method of vegetational analysis. Northwest Science 33:43-64

Dauwalter DC, Fisher WL, Belt KC (2006) Mapping stream habitats with a global positioning system: accuracy, precision, and comparison with traditional methods. Environmental Management 37:271-280

Feldesman MR (2002) Classification trees as an alternative to linear discriminant analysis. American Journal of Physical Anthropology 119:257-275

Fisher RJ, Davis SK (2010) From Wiens to Robel: a review of grassland-bird habitat selection. Journal of Wildlife Management 74:264-273
Frank AB, Dugas WA (2001) Carbon dioxide fluxes over a northern, semiarid, mixed-grass prairie. Agricultural and Forest Meteorology 108:317-326

Fujisada H (1998) ASTER Level-1 data processing algorithm. IEEE Transactions on Geoscience and Remote Sensing 36:1101-1112

Gesch DM, Oimoen S, Greenlee S, Nelson M, Steuck M, Tyler D (2002) The national elevation dataset. Photogrammetric Engineering and Remote Sensing 68:5-11

Hall K, Johansson LJ, Sykes MT, Reitalu T, Larsson K, Prentice HC (2010) Inventorying management status and plant species richness in seminatural grasslands using high spatial resolution imagery. Applied Vegetation Science 13:221-233

Hansen K (2008) Plants of the Grand River and Cedar River national grasslands. US Department of Agriculture Dakota Prairie Grasslands, Washington, DC. http://www.fs.fed.us/r1/dakota prairie. Accessed 20 June 2010

Hardinsky MA, Klemas V, Smart RM (1983) The influence of soilsalinity, growth form, and leaf moisture on the spectral radiance of Spartina alterniflora canopies. Photogrammetric Engineering and Remote Sensing 49:77-83

Holifield Collins CD, Emmerich WE, Moran MS, Hernandez M, Scott RL, Bryant RB, King DM, Verdugo CL (2008) A remote sensing approach for estimating distributed daily net carbon dioxide flux in semiarid grasslands. Water Resources Research 44:W05S17W05S18. doi:10.1029/2006WR005699

Huete A, Didan K, Miura T, Rodriguez EP, Gao X, Ferreira LG (2002) Overview of the radiometric and biophysical performance of the MODIS vegetation indices. Remote Sensing of Environment 83:195-213

Hunt RE, Jr, Everitt JH, Ritchie JC, Moran MS, Booth DT, Anderson GL, Clark PE, Seyfried MS (2003) Applications and research using remote sensing for rangeland management. Photogrammetric Engineering \& Remote Sensing 69:675-693

Hunt ER, Rock BN (1989) Detection of changes in leaf water content using near- and middle-infrared reflectance. Remote Sensing of Environment 40:33-54

Jenness J (2006) Topographic position index (tpi_jen.avx) extension for ArcView 3.x, v 1.2. Jenness Enterprises. http://ww.jennessent. com/arcview/tpi.htm. Accessed 3 June 2010

Knapp AK, Fahnestock JT, Hamburg SP, Statland LB, Seastedt TR, Schimel DS (1993) Landscape patterns in soil-plant water relations and primary production in tallgrass prairie. Ecology 74 : $549-560$

Larivière S (2003) Edge effects, predator movements, and the travellane paradox. Wildlife Society Bulletin 31:315-320

Lawrence RL, Ripple WJ (1998) Comparisons among vegetation indices and bandwise regression in a highly disturbed, heterogeneous landscape: Mount St Helens, Washington. Remote Sensing of Environment 64:91-102

Luoto M, Virkkala R, Heikkinen RK, Rainior K (2004) Predicting bird species richness using remote sensing in boreal agriculturalforest mosaics. Ecological Applications 14:1946-1962

MacMillan RA, Pettapiece WW, Nolan SC, Goddard TW (2000) A generic procedure for automatically segmenting landforms into landform elements using DEMs, heuristic rules and fuzzy logic. Fuzzy Sets and Systems 113:81-109

Markham BL, Barker JL (1987) Radiometric properties of U.S. processed Landsat MSS data. Remote Sensing of Environment 22:39-71

Marsett RC, Qi J, Heilman P, Biedenbender SH, Watson MC, Amer S, Weltz M, Goodrich D, Marsett R (2006) Remote sensing for grassland management in the arid southwest. Range Ecology and Management 59:530-540

Milchunas DG, Lauenroth WK (1993) Quantitative effects of grazing on vegetation and soils over a global range of environments. Ecological Monographs 63(4):327-366 
Milchunas DG, Laenroth WK, Chapman PL, Kazempour MK (1989) Effects of grazing, topography, and precipitation on the structure of a semiarid grassland. Vegetatio 80:11-23

Moran MS, Inoue Y, Barnes EM (1997) Opportunities and limitations for Image-based remote sensing in precision crop management. Remote Sensing of Environment 61:319-346

NDAWN hourly data (2000) NDSU-NDAWN, Fargo. http://ndawn. ndsu.nodak.edu/. Accessed 20 Aug 2011

NRCS Official Soil Series Descriptions. United States Department of Agriculture. http://soils.usda.gov/technical/classification/osd/index. html. Accessed 10 February 2011

Omernik JM (1987) Ecoregions of the conterminous United States. Annals of Association of American Geographers 77(1):118-125

Qi J, Chehbouni A, Huete A, Kerr YH, Sorooshian S (1994) A modified soil adjusted vegetation index. Remote Sensing of Environment 48:119-126

Qin CZ, Zhu AX, Shi X, Li BL, Pei T, Zhou CH (2009) Quantification of spatial gradation of slope positions. Geomorphology 110:152-161

R Development Core Team (2009) R: a language and environment for statistical computing. R Foundation for Statistical Computing, Vienna. http://R-project.org. Accessed 3 Sept 2010

Robel RJ, Briggs JN, Dayton AD, Hulbert LC (1970) Relationships between visual obstruction measurements and weight of grassland vegetation. Journal of Range Management 23:296-297

Roberts DA, Batista G, Pereira JLG, Waller E, Nelson B (1998) Change identification using multitemporal spectral mixture analysis: application in eastern Amazonia. In: Elvidge C, Lunetta R (eds) Remote sensing change detection: environ monitoring applications and methods. Ann Arbor Press, Ann Arbor, pp 137-161

Singh JS, Milchunas DG, Lauenroth WK (1998) Soil water dynamics and vegetation patterns in a semiarid grassland. Plant Ecology 134:77-89
Sjursen P (2009) Grand River National Grassland Robel pole inventory. U.S. Forest Service, Bismarck

Svingen D (2009) Grassland bird management on public lands in the United States: an example from the northern Great Plains. In: Proceedings of the fourth international partners in flight conference: tundra to tropics, pp 590-593

Tonooka H, Sakuma F, Kudoh M, Iwafune K (2003) ASTER/TIR onboard calibration status and user-based recalibration. In: Proceedings of the Society of Photo-Optical Instrumentation Engineers, pp 191-201

Uresk DW, Benson TA (2007) Monitoring with a modified Robel pole on meadows in the central Black Hills of South Dakota. West North American Naturalist 67:46-50

Uresk DW, Juntti TM (2008) Monitoring Idaho fescue grasslands in the Big Horn Mountains, Wyoming, with a modified Robel pole. West North American Naturalist 68:1-7

Vermiere LT, Ganguli AC, Gillen RL (2002) A robust model for estimating standing crop across vegetation types. Journal of Range Management 55:494-497

Vermiere LT, Gillen RL (2001) Estimating herbage standing crop with visual obstruction in tallgrass prairie. Journal of Range Management 54:57-60

Washington-Allen RA, West NE, Ramsey RD, Efroymson RA (2006) A protocol for retrospective remote sensing-based ecological monitoring of rangelands. Range Ecology and Management 59(1):19-29

Wood J (1996) Scale-based characterization of digital elevation models. In: Parker D (ed) Innovations in GIS 3. Taylor and Francis, London, pp 163-175 